\title{
Diet-induced Hyperlipoproteinemia and Atherosclerosis in Apolipoprotein E3-Leiden Transgenic Mice
}

\author{
Bart J. M. van Vlijmen, * Arn M. J. M. van den Maagdenberg, ${ }^{*}$ Marion J. J. Gijbels, * Hans van der Boom, " Harm HogenEsch, * \\ Rune R. Frants, ${ }^{\star}$ Marten H. Hofker, ${ }^{\ddagger}$ and Louis M. Havekes* \\ ${ }^{*}$ TNO Institute of Ageing and Vascular Research, Gaubius Laboratory, 2300 AK Leiden; and ${ }^{\ddagger}$ Department of Human Genetics, Leiden \\ University, 2300 AK Leiden, The Netherlands
}

\begin{abstract}
Apolipoprotein E3-Leiden (APOE *3-Leiden) transgenic mice have been used to study the effect of different cholesterol-containing diets on the remnant lipoprotein levels and composition and on the possible concurrent development of atherosclerotic plaques. On high fat/cholesterol (HFC) diet, the high expressing lines 2 and 181 developed severe hypercholesterolemia (up to 40 and $60 \mathrm{mmol} /$ liter, respectively), whereas triglyceride levels remained almost normal when compared with regular mouse diet. The addition of cholate increased the hypercholesterolemic effect of this diet. In lines 2 and 181, serum levels of apo E3-Leiden also increased dramatically upon cholesterol feeding (up to 107 and $300 \mathrm{mg} / \mathrm{dl}$, respectively). In these high expressing APOE*3-Leiden transgenic mice, the increase in both serum cholesterol and apo E3-Leiden occurred mainly in the VLDL/LDL-sized fractions, whereas a considerable increase in large, apo E-rich HDL particles also occurred. In contrast to the high expressing lines, the low expressing line 195 reacted only mildly upon $\mathrm{HFC}$ diet.

On HFC diets, the high expresser APOE*3-Leiden mice developed atherosclerotic lesions in the aortic arch, the descending aorta, and the carotid arteries, varying from fatty streaks containing foam cells to severe atherosclerotic plaques containing cholesterol crystals, fibrosis, and necrotic calcified tissue. Quantitative evaluation revealed that the atherogenesis is positively correlated with the serum level of cholesterol-rich VLDL/LDL particles. In conclusion, with APOE*3-Leiden transgenic mice, factors can be studied that influence the metabolism of remnant VLDL and the development of atherosclerosis. (J. Clin. Invest. 1994. 93:1403-1410.) Key words: familial dysbetalipoproteinemia • atherosclerotic plaques • cholesterolrich diets $\bullet$ hypercholesterolemia $\bullet$ hypertriglyceridemia
\end{abstract}

\section{Introduction}

Apolipoprotein $\mathrm{E}$ functions as a ligand for the receptor-mediated uptake of chylomicron and VLDL remnants by hepatic lipoprotein receptors (1-3). Normally, these remnant particles

Address correspondence to Dr. L. M. Havekes, IVVO-TNO, Gaubius Laboratory, P.O. Box 430, 2300 AK Leiden, The Netherlands. H. HogenEsch's present address is Purdue University, School of Veterinary Medicine, Department of Pathobiology, West Lafayette, IN 47907.

Received for publication 2 September 1993 and in revised form 7 December 1993.

J. Clin. Invest.

(c) The American Society for Clinical Investigation, Inc. $0021-9738 / 94 / 04 / 1403 / 08 \quad \$ 2.00$

Volume 93, April 1994, 1403-1410 are rapidly removed from the circulation. However, in humans, mutations in the structural gene for apo $\mathrm{E}$ can lead to a binding-defective apo $\mathrm{E}$ and, consequently, to a reduced clearance rate of remnant particles, as has been described for patients with familial dysbetalipoproteinemia (FD) ${ }^{1}(4,5)$. The accumulation of atherogenic remnant particles in the plasma of FD patients results in a predisposition for coronary and/or peripheral atherosclerosis (5).

In most cases, FD is associated with homozygosity for the APOE*2(Arg 158 $\rightarrow$ Cys) allele (5). However, heterozygosity for the rare $\mathrm{APOE}^{*} 3$-Leiden allele is also associated with FD (6). Thus in the case of APOE*3-Leiden heterozygosity, FD is inherited in a dominant fashion. Among all homozygous APOE*2(Arg $158 \rightarrow$ Cys) subjects ( $1 \%$ in the general population), only a small proportion $(\sim 4 \%)$ develops FD at a later age. Hence, additional factors are required for the expression of the disease. Known factors that strongly influence the severity of FD are age, gender, nutritional status, and body mass index (5). Although almost all heterozygous APOE*3-Leiden subjects display FD, also in these subjects the severity of the disease is largely dependent on additional environmental and/or genetic factors (6).

Studying the (subtle) environmental and genetic factors influencing remnant metabolism and atherosclerosis in humans, numerous limitations are encountered: relevant environmental variables are often hard to control; detailed biochemical studies in humans are frequently not allowed; and humans exhibit a considerable heterogeneity in genetic background whereas the number of subjects carrying specific mutations or combinations of specific mutations are usually very limited.

For the study of genetic and environmental factors which modulate the lipoprotein remnant metabolism and the development of atherosclerosis in vivo in a more standardized way, we studied in this paper the feasibility of transgenic mice. Since conventional transgenesis implies the addition of extra copies of genes to the genome, only dominant effects can be studied using this approach. Therefore, we chose the dominant APOE*3-Leiden gene as a transgene. Recently, we reported the generation of three different APOE*3-Leiden/APOC1 transgenic mouse lines $(2,181$, and 195) with different levels of expression of the APOE*3-Leiden gene (7). It appeared that these transgenic mice developed hyperlipidemia, which was positively correlated with the level of expression of the transgene, even on a regular mouse diet. Furthermore, the high expressing line 181 appeared to be highly responsive to cholesterol-rich diets with regard to serum cholesterol levels in the

1. Abbreviations used in this paper: FD, familial dysbetalipoproteinemia; HFC, high fat/cholesterol; HPS, hematoxylin-phloxine-saffron; HRP, horseradish peroxidase; IDL, intermediate density lipoprotein; LFC, low fat/cholesterol; SRM-A, standard rat mouse diet. 
VLDL/LDL-sized fractions. The human APOC1 gene was also included in the transgene in order to be able to introduce simultaneously the endogenous DNA sequence that is responsible for the liver-specific expression of the APOE gene. The potential contribution of the APOC1 gene to the phenotypic expression of these lines can be excluded as transgenic mice with a high level expression of a similar but wild-type APOEAPOC1 transgene do not express hyperlipidemia $(8,9)$.

In this paper, we used these $\mathrm{APOE}^{*} 3$-Leiden transgenic mice to study the effect of different semisynthetic cholesterolcontaining diets on the remnant lipoprotein levels and composition and on the possible concurrent development of atherosclerotic plaques. These mice develop atherosclerotic plaques of which the severity is positively correlated with the serum levels of cholesterol-rich VLDL/LDL-sized lipoproteins and the level of expression of the APOE*3-Leiden transgene. We can conclude that the APOE*3-Leiden transgenic mice offer a suitable animal model system for studying the environmental factors involved in remnant metabolism and concurrent atherogenesis.

\section{Methods}

Animals. Transgenic mice of lines 2, 181, and 195, expressing human APOE*3-Leiden and human APOC1 genes were generated previously (7). Microinjection has been performed in eggs from (C57BL/6J $\times$ CBA/J) F1 females that had been mated to males of the same genetic background. Transgenic and nontransgenic littermates were obtained by breeding with $\mathrm{C} 57 \mathrm{BL} / 6 \mathrm{~J}$ mice. Mice of $\mathrm{F} 2$ generation have been used for the experiment. Identification of transgenic mice was done by PCR analysis on genomic tail DNA, as described before (7). Mice of the F2 generation, 8-10 wk of age, were included in the experiments. Males and females were equally distributed among the various groups. Before the diet administration, mice were housed under standard conditions in conventional cages and were given free access to water and regular mouse diet. Diets were administered to groups of at least five mice of each line. Blood samples were taken before and after 6 wk of feeding. Also, during diet feeding, mice were given free access to food and water. Animal weights were not significantly different between diets after $6 \mathrm{wk}$ of diet feeding. None of the transgenic or nontransgenic mice were lost during the entire study of $14 \mathrm{wk}$.

Composition of the diets. Before starting the dietary treatment, mice were fed regular mouse diet (standard rat mouse diet [SRM-A]; Hope Farms, Woerden, The Netherlands). The three semisynthetic diets were composed essentially according to Nishina et al. (10), and were purchased from Hope Farms. The compositions of the different diets are given in Table I. The basic diet, containing only sucrose and basic nutrients, is designated as the low fat/cholesterol (LFC) diet. Two diets consist of the basic diet supplemented with cocoa butter (15\%, by weight) and cholesterol (1\%, by weight) and represent the high fat/ cholesterol (HFC) diets. These two diets differ in amounts of added cholate $(0.1$ and $0.5 \%$, by weight ) and are designated as $\mathrm{HFC} / 0.1 \%$ and HFC $/ 0.5 \%$, respectively. Cholate was added to facilitate intestinal uptake of fat and cholesterol.

Lipid and lipoprotein analysis. After a 12-h fasting period, $\sim 300$ $\mu \mathrm{l}$ of blood was obtained from each individual mouse through tail bleeding. Total serum cholesterol and triglyceride levels (without free glycerol) were measured enzymatically using commercially available kits (236691 and 877557, respectively; Boehringer Mannheim GmbH, Mannheim, Germany).

For size fractionation of lipoproteins, $150 \mu \mathrm{l}$ of pooled serum (from at least three mice per group) was applied to a 25-ml Superose 6B column (Pharmacia AB, Uppsala, Sweden) connected to an HPLC pump system and was eluted at a constant rate of $0.5 \mathrm{ml} / \mathrm{min}$ with PBS ( $\mathrm{pH} 7.4$ ). The effluent was collected in $0.5-\mathrm{ml}$ fractions. Cholesterol
Table I. Composition of the Semisynthetic Diets

\begin{tabular}{lccc}
\hline \multirow{2}{*}{$\begin{array}{c}\text { Diet } \\
\text { components }\end{array}$} & LFC & HFC/0.1\% & HFC $/ 0.5 \%$ \\
\cline { 2 - 4 } & & g/100 g diet \\
Cocoa butter & - & 15 & 15 \\
Cholate & - & 0.1 & 0.5 \\
Cholesterol & - & 1 & 1 \\
Sucrose & 50.5 & 40.5 & 40.5 \\
Cornstarch & 12.2 & 10 & 10 \\
Corn oil & 5 & 1 & 1 \\
Cellulose & 5 & 5.1 & 4.7 \\
\hline
\end{tabular}

In addition, all diets contained $20 \%$ casein, $1 \%$ choline chloride, $0.2 \%$ methionine, and $5.1 \%$ mineral mixture. All percentages are in weight/weight. Energy contents of the three diets was $3,883 \mathrm{kcal} / \mathrm{kg}$ for the LFC diet and $4,356 \mathrm{kcal} / \mathrm{kg}$ for both HFC diets.

and triglyceride concentrations in lipoprotein fractions were measured enzymatically, as described above.

Apo B/apo E-containing lipoproteins were precipitated by mixing $200 \mu$ l of pooled serum (from three mice per group) with $20 \mu \mathrm{l}$ of $4 \%$ sodium phosphotungstic acid (11). Subsequently, $10 \mu \mathrm{l}$ of $1 \mathrm{M} \mathrm{MgCl}_{2}$ was added, and the mixture was kept at room temperature for $30 \mathrm{~min}$. Thereafter, samples were centrifuged for $30 \mathrm{~min}$ in a minifuge. Some $150 \mu$ l of the supernatant was applied to a Superose 6B column (Pharmacia $A B$ ), as described above. The amount of precipitable HDL cholesterol was calculated as the difference of the total area under the curve of HDL fractions 31-41 of lipoprotein profiles before and after precipitation and was corrected for sample dilution in case of precipitation.

Quantitation of human apo $E$. Human apo E concentrations were measured by sandwich ELISA. Affinity-purified polyclonal goat antihuman apo $\mathrm{E}$ antibodies were used for coating. Affinity-purified polyclonal rabbit anti-human apo $\mathrm{E}$ antibodies were used as second antibodies. Thereafter, the plates were incubated with swine anti-rabbit IgG antibodies conjugated with horseradish peroxidase (HRP). Finally, HRP detection was performed using HRP substrate tetramethylbenzidine. Pooled plasma from healthy human subjects with known apo E level was used as a standard.

Histological assessment of atherosclerosis. After $14 \mathrm{wk}$ of diet feeding, mice were killed. A complete gross necropsy was performed, and the entire aorta from the aortic valves to the iliac bifurcation was dissected. In addition, parathymic fat tissue was sampled to screen for the presence of arterial lesions in the carotid arteries. After phosphate-buffered formalin fixation, the heart was trimmed according to a modified method of Paigen et al. (12). In brief, the heart and the ascending aorta were cut perpendicular to the heart axis at four levels: $(a)$ just beneath the atrial tips, $(b)$ through the aorta and just above the atria, $(c)$ at the level of the aortic sinus and the aortic valves, and $(d)$ between aortic sinus and level $a$. In total, four heart sections were microscopically examined. The proximal $0.5 \mathrm{~cm}$ of aorta ascendens and aortic arch were divided into two parts for transverse sections. The remainder of the thoracic and abdominal aorta was divided into two parts for transverse and longitudinal sections. All tissue samples were dehydrated and paraffin embedded. 3- $\mu \mathrm{m}$ sections were routinely stained with hematoxylin-phloxine-saffron (HPS). Additional stains used were Verhoeff's, van Gieson's, and von Kossa's silver stain. The total arterial endothelial surface examined was comparable for all animals.

For semiquantitative assessment, the arterial lesions were classified into five categories: (1) early fatty streak: per section up to 10 foam cells present in the intima, (2) regular fatty streak: more than 10 foam cells present in the intima, (3) mild plaque: extension of foam cells into 
the media and mild fibrosis of the media without loss of architecture, (4) moderate plaque: foam cells in the media, fibrosis, cholesterol clefts, mineralization and/or necrosis of the media, and (5) severe plaque: as 4 but more extensive and deeper into the media. Every individual arterial lesion was classified accordingly. Within a group the total number of both mild lesions (categories 1-3) and moderate plus severe lesions (categories 4 and 5 ) of all mice was counted. After dividing the total number of lesions (mild and moderate plus severe, separately) by the number of mice per group, two separate mean scores for each group of animals were obtained.

Statistical analysis. Number Cruncher Statistical System version 5.02 (Kaysville, UT) was used for statistical analysis. Since the transgenic and nontransgenic mice were littermates and measured lipid parameters showed non-Gaussian distributions, we used nonparametric tests for statistical analysis. Mann-Whitney rank sum test was used when two groups were compared. $P$ values $<0.05$ were regarded as significant.

\section{Results}

Effect of different diets on serum lipid and apo E3-Leiden levels. When kept on SRM-A, serum cholesterol and triglyceride levels were significantly higher in transgenic lines 2 and 181 mice than in nontransgenic littermates (Table II). In transgenic line 195 mice elevations of serum lipid levels did not reach statistical significance. The serum levels of apo E3-Leiden correlated well with the extent of hyperlipidemia in the transgenic mice.

After 6 wk on the LFC diet, lines 2 and 181 mice showed a strong increase in serum cholesterol (two- and threefold, respectively) and serum triglyceride levels (2- and 11-fold, respectively). Mean apo E3-Leiden levels in these transgenic mice also increased significantly (up to 54 and $147 \mathrm{mg} / \mathrm{dl}$, respectively). Line 195 mice did not show a strong increase in serum lipid levels on LFC diet compared with the control mice ( Table II).

Feeding transgenic lines 2 and 181 mice the $\mathrm{HFC} / 0.1 \%$ diet resulted in a dramatic rise in serum cholesterol levels, while serum triglyceride levels decreased relative to the LFC diet ( $\mathrm{Ta}$ ble II). The apo E3-Leiden level in lines 2 and 181 mice on HFC $/ 0.1 \%$ diet also increased to extremely high levels: 107 and $300 \mathrm{mg} / \mathrm{dl}$, respectively. Further increasing the cholate content up to $0.5 \%$ (HFC $/ 0.5 \%$ diet) resulted in a further increase in cholesterol levels, whereas the opposite effect was observed for serum triglycerides and serum apo E3-Leiden levels. Again, only a moderate response on serum lipid levels during these diets was observed for the low expressing line 195 and control mice. In the transgenic line 195 mice, apo E3-Leiden levels remained low during all three diet regimens.

Apo E3-Leiden and serum lipid levels. The results presented in Table II suggest a differential effect on serum apo E3-Leiden and serum cholesterol levels in lines 2 and 181 mice when being fed different diets. To further demonstrate this, for each line separately, the mean level of apo E3-Leiden is plotted against the corresponding mean serum cholesterol level obtained per diet, as indicated (Fig. 1). Strikingly, for both lines 2 and 181 the highest apo E3-Leiden levels were found after the $\mathrm{HFC} / 0.1 \%$ diet rather than after the most severe hypercholesterolemic $\mathrm{HFC} / 0.5 \%$ diet. In contrast to these observations, in line 195 mice no such relationship was observed.

Distribution of lipids and apo E3-Leiden among lipoprotein fractions after different diets. Because of the differential effect of the three diets on cholesterol and triglyceride levels (Table II) and the absence of a linear correlation between mean serum cholesterol and mean apo E3-Leiden levels as shown in Fig. 1, we evaluated the distribution of cholesterol, triglyceride, and apo E3-Leiden among the various lipoprotein

Table II. Serum Lipid and Lipoprotein Concentrations after 6 Wk of Dietary Treatment

\begin{tabular}{|c|c|c|c|c|c|c|c|c|c|c|c|c|c|}
\hline \multirow{3}{*}{$\begin{array}{l}\text { Mouse } \\
\text { line }\end{array}$} & & \multirow{2}{*}{\multicolumn{3}{|c|}{ SRM-A }} & \multicolumn{9}{|c|}{ Diet } \\
\hline & & & & & \multicolumn{3}{|c|}{ LFC } & \multicolumn{3}{|c|}{$\mathrm{HFC} / 0.1 \%$} & \multicolumn{3}{|c|}{ HFC $/ 0.5 \%$} \\
\hline & & TC & TG & apo $E$ & TC & TG & apo $E$ & TC & TG & apo $\mathrm{E}$ & $\mathrm{TC}$ & TG & apo $E$ \\
\hline & & \multicolumn{2}{|c|}{$\mathrm{mmol} / \mathrm{liter}$} & $m g / d l$ & \multicolumn{2}{|c|}{$\mathrm{mmol} / \mathrm{liter}$} & $m g / d l$ & \multicolumn{2}{|c|}{ mmol/liter } & $m g / d l$ & \multicolumn{2}{|c|}{$\mathrm{mmol} / \mathrm{liter}$} & $m g / d l$ \\
\hline \multirow[t]{4}{*}{2} & Total & $3.2 \pm 0.7^{*}$ & $2.7 \pm 0.7^{*}$ & $36 \pm 18$ & $6.4 \pm 0.4^{* t}$ & $5.4 \pm 1.1^{* \ddagger}$ & $54 \pm 13$ & $26.2 \pm 1.5^{* \ddagger}$ & $3.3 \pm 0.4^{*}$ & $107 \pm 42^{\ddagger}$ & $39.9 \pm 9.0^{* \neq}$ & $1.6 \pm 0.1^{*}$ & $68 \pm 14^{\ddagger}$ \\
\hline & VLDL & 1.4 & 2.1 & ND & 2.3 & 3.9 & 1.9 & 13.0 & 2.0 & 6.9 & 21.1 & 1.1 & 12.3 \\
\hline & IDL/LDL & 0.5 & 0.5 & ND & 1.4 & 0.9 & 12.4 & 7.0 & 0.6 & 43.7 & 10.7 & 0.3 & 28.1 \\
\hline & HDL & 1.2 & 0.2 & 36.0 & 2.8 & 0.5 & 39.7 & 6.3 & 0.7 & 56.5 & 8.1 & 0.2 & 27.6 \\
\hline \multirow[t]{4}{*}{181} & Total & $4.8 \pm 1.3^{*}$ & $2.7 \pm 1.0^{*}$ & $91 \pm 28$ & $13.3 \pm 1.9^{* \neq}$ & $29.4 \pm 9.4^{\text {*‡ }}$ & $147 \pm 9^{\ddagger}$ & $43.7 \pm 13.2^{* \neq}$ & $10.5 \pm 3.7^{\text {*‡ }}$ & $300 \pm 78^{\ddagger}$ & $59.1 \pm 9.8^{* \pm}$ & $4.5 \pm 2.3^{* \pm}$ & $189 \pm 71^{\ddagger}$ \\
\hline & VLDL & 1.8 & 2.3 & 0.2 & 8.1 & 23.2 & 21.7 & 27.1 & 8.5 & 44.4 & 39.2 & 3.6 & 38.9 \\
\hline & IDL/LDL & 0.5 & 0.3 & ND & 1.7 & 3.7 & 7.3 & 8.2 & 1.4 & 80.0 & 11.3 & 0.5 & 73.9 \\
\hline & HDL & 2.4 & 0.1 & 90.8 & 3.5 & 2.4 & 117.8 & 8.1 & 0.6 & 175.6 & 8.6 & 0.3 & 76.2 \\
\hline \multirow[t]{4}{*}{195} & Total & $2.5 \pm 0.4$ & $0.7 \pm 0.2$ & $3 \pm 1$ & $3.1 \pm 1.0$ & $0.5 \pm 0.3$ & $4 \pm 1^{\ddagger}$ & $4.1 \pm 0.7^{* \pm}$ & $0.3 \pm 0.2$ & $2 \pm 1$ & $8.1 \pm 1.7^{* \pm}$ & $0.3 \pm 0.4^{\text {*t }}$ & $2 \pm 1$ \\
\hline & VLDL & 0.1 & 0.3 & ND & 0.3 & 0.2 & ND & 0.9 & 0.1 & ND & 3.9 & 0.1 & 0.6 \\
\hline & IDL/LDL & 0.2 & 0.2 & ND & 0.4 & 0.1 & 0.3 & 0.7 & 0.1 & 0.3 & 1.5 & 0.1 & 0.3 \\
\hline & HDL & 2.2 & 0.3 & 3.0 & 2.4 & 0.2 & 3.7 & 2.5 & 0.1 & 1.8 & 2.7 & 0.1 & 1.1 \\
\hline \multirow[t]{4}{*}{ Control } & Total & $2.1 \pm 0.3$ & $0.5 \pm 0.3$ & - & $2.9 \pm 0.2^{\ddagger}$ & $0.6 \pm 0.2$ & - & $2.8 \pm 0.5^{\ddagger}$ & $0.1 \pm 0.1^{\ddagger}$ & - & $5.7 \pm 1.6^{\ddagger}$ & $0.1 \pm 0.1^{\ddagger}$ & - \\
\hline & VLDL & 0.2 & 0.2 & - & 0.3 & 0.4 & - & 0.3 & 0.1 & - & 2.5 & 0.1 & - \\
\hline & IDL/LDL & 0.1 & 0.1 & - & 0.4 & 0.1 & - & 0.3 & 0.1 & - & 1.2 & 0.1 & - \\
\hline & HDL & 1.8 & 0.2 & - & 2.2 & 0.1 & - & 2.2 & 0.1 & - & 1.9 & 0.1 & - \\
\hline
\end{tabular}

TC, total cholesterol (free plus esterified); TG, triglyceride; apo E, apo E3-Leiden. Total cholesterol, triglyceride, and apo E3-Leiden values are the mean serum levels \pm SD of five mice per group. $* P<0.05$, indicating the difference between transgenic and nontransgenic groups of mice on the same diet, using nonparametric Mann-Whitney tests. ${ }^{\ddagger} P<0.05$, indicating the difference between semisynthetic diet and regular SRM-A within each line, using nonparametric Mann-Whitney. The cholesterol, triglycerides, and apo E in VLDL, IDL/LDL, and HDL were calculated from the serum total cholesterol, triglycerides, and apo E and the area under the curve in the lipoprotein profile (as determined by gel filtration chromatography using a Superose 6B column [Pharmacia AB]). As observed in control mice on SRM-A fraction, numbers 20-25, 26-30, and 31-41 correspond to VLDL, IDL/LDL, and HDL, respectively. ND, not detectable. 


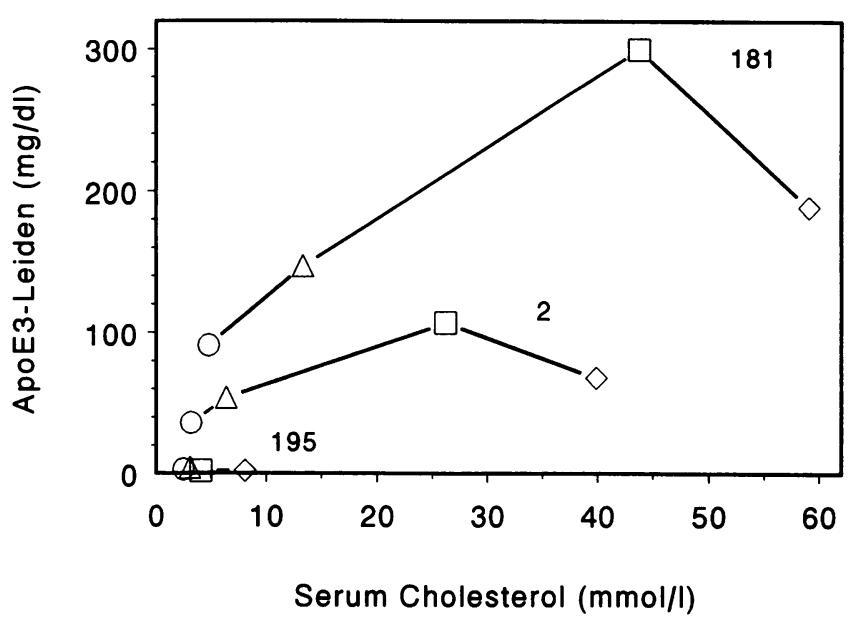

Figure 1. Correlation between mean serum cholesterol and human apo E3-Leiden levels in transgenic mice of lines 181, 2, and 195. The values are obtained from Table II and represent mean levels after feeding transgenic mice SRM-A $(0), \operatorname{LFC}(\Delta), \operatorname{HFC} / 0.1 \%(\square)$, or $\mathrm{HFC} / 0.5 \%(\diamond)$ for $6 \mathrm{wk}$.

fractions. Therefore, serum lipoproteins were size fractionated, using Superose 6B (Pharmacia AB) gel permeation chromatography. In Fig. 2 lipoprotein profiles are shown for transgenic line 181 mice after 6 wk of SRM-A diet $(a)$ and after 6 wk of three semisynthetic diets $(b, c$, and $d)$. For all three semisynthetic diets, the increase in cholesterol was most prominent in the VLDL- and intermediate density lipoprotein (IDL)/LDLsized fractions. In addition, triglycerides were almost exclusively confined to these fractions. Strikingly, as compared with the LFC diet, feeding the HFC diets leads to VLDL- and IDL/ LDL-sized fractions that are relatively rich in cholesterol, in particular with higher percentages of cholate (compare $b$ with $c$ and $c$ with $d$ ). A similar dietary response was found for line 2 mice (results not shown).

A quantification of the lipid distribution among the various lipoprotein fractions is presented in Table II for all three lines and control mice. In addition to a cholesterol increase in the VLDL- and IDL/LDL-sized fractions, a cholesterol increase was also observed in the HDL-sized fractions of the transgenic lines 2 and 181 with the HFC diets. On the contrary, in line 195 and in the nontransgenic littermates HDL cholesterol was not influenced by cholesterol feeding. As shown for line 181 in Fig. 2 , the increase in HDL cholesterol is mainly because of an increase in the fraction of larger HDL particles. This suggests the generation of apo E-rich HDL particles with cholesterol feeding. To investigate this further, lipoprotein gel permeation profiles were made before and after precipitation of apo B/apo E-containing lipoproteins in serum with sodium phosphotungstic acid (Fig. 3). In nontransgenic littermates (control mice) only a small proportion of the HDL fraction is precipitable, irrespective of cholesterol feeding. On the contrary, in line 181 a major proportion of the HDL cholesterol could be precipitated together with the VLDL- and IDL/LDL-sized fractions, both after cholesterol feeding and after a regular SRM-A diet. Similar experiments have been carried out for lines 2 and 195 and control mice. We calculated that on HFC $/ 0.1 \%$ diet the major proportion of HDL cholesterol is precipitable in lines 181 and 2 ( 85 and $80 \%$, respectively), whereas in line 195 and in nontransgenic littermates this proportion is much lower (40 and $8 \%$, respectively).

Table II also presents the quantitative distribution of apo E3-Leiden protein among the various lipoprotein fractions. For all three lines the HDL fraction is the major apo E3-Leiden-containing lipoprotein fraction, after the application of each diet regime. In addition, in lines 2 and 181 cholesterol feeding also resulted in a dramatic increase in the amount of apo E3-Leiden present in the VLDL- and IDL/LDL-sized fractions. In line 195 only very low amounts of apo E3-Leiden appear in the VLDL-and IDL/LDL-sized fraction when being fed cholesterol.

Histological assessment of atherosclerosis. The results presented above indicate that in mice of lines 2 and 181, when fed either the $\mathrm{HFC} / 0.1 \%$ or $\mathrm{HFC} / 0.5 \%$ diet, an accumulation in the plasma of cholesterol-rich remnant lipoproteins occurred to an extent which can be considered as atherogenic. Atherogenesis in mice, after administration of the different diets, was assessed by histological analyses. After being fed the diets for a period of $14 \mathrm{wk}$, each group of transgenic mice was analyzed for development of atherosclerotic lesions in the aortic arch,
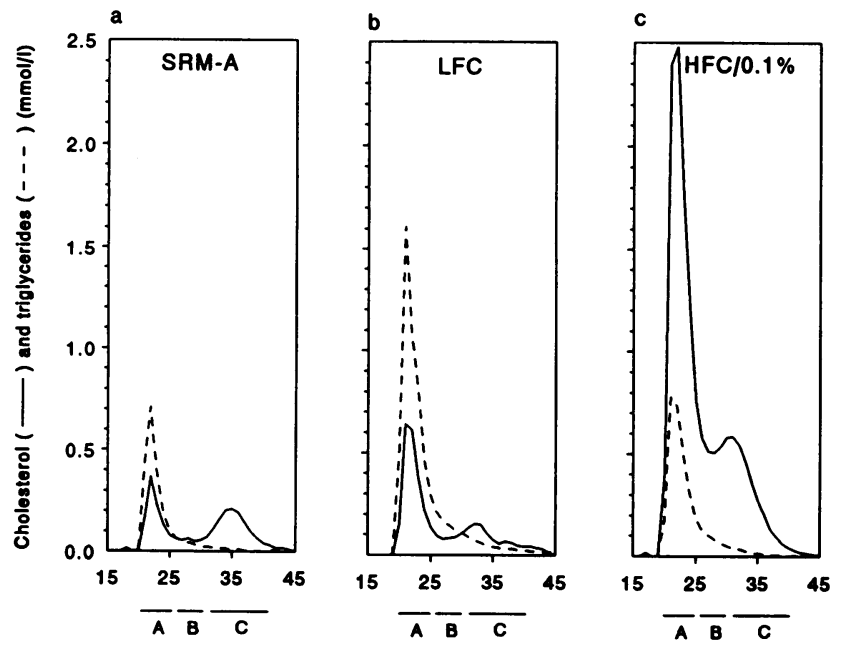

Fraction number

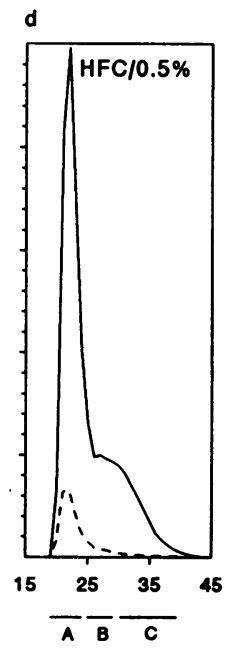

Figure 2. Distribution of serum cholesterol and triglycerides among lipoprotein fractions. Lipoprotein fractions were separated by gel filtration chromatography using a 25-ml Superose 6B column (Pharmacia AB) as described in Methods. Lipoprotein profiles are shown for transgenic line 181 mice fed SRM-A or one of the specified diets (LFC, $\mathrm{HFC} / 0.1 \%$, and HFC $/ 0.5 \%$ ) for $6 \mathrm{wk}$. Each run is performed with a pool of serum of at least three mice of the same group. Fractions corresponding to VLDL, IDL/LDL, and HDL (as observed in nontransgenic mice on SRM-A) are indicated by bars $A, B$, and $C$, respectively. 

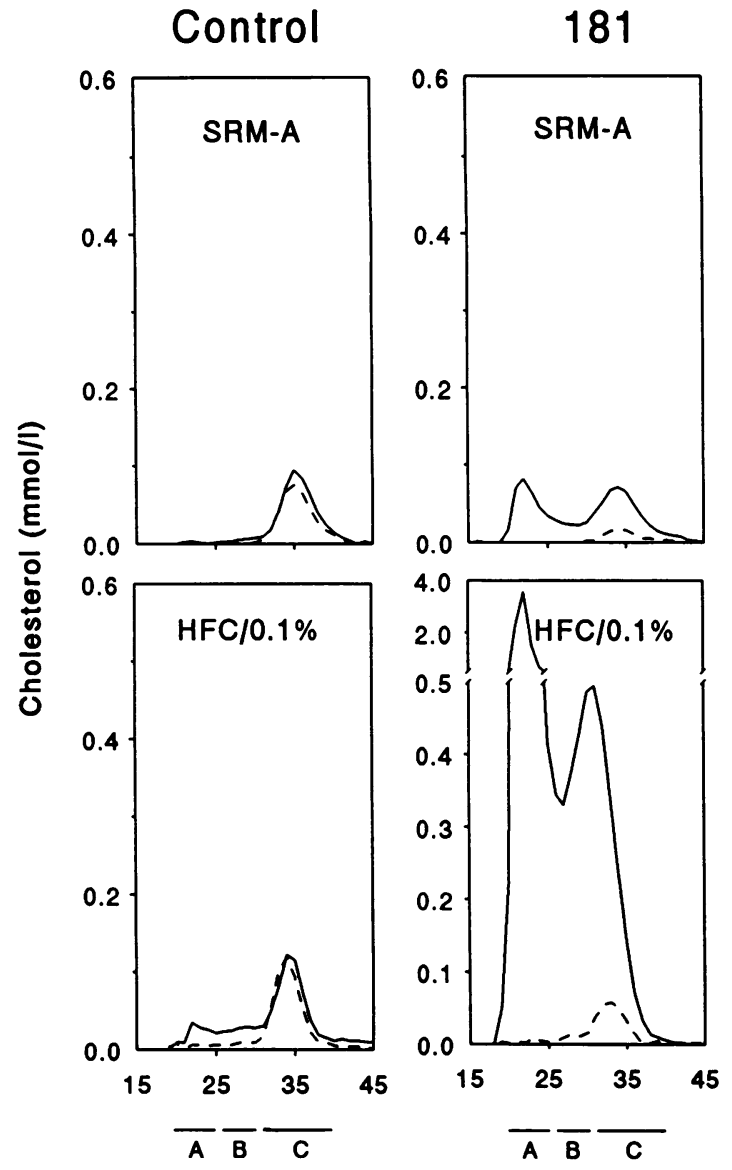

\section{Fraction number}

Figure 3. Distribution of serum cholesterol among lipoprotein fractions before (solid line) and after (dotted line) precipitation of apo B/E-containing lipoproteins. Apo B/E-containing lipoproteins are precipitated with sodium phosphotungstic acid as described in Methods. Cholesterol profiles for nontransgenic mice and transgenic line 181 mice are given as indicated after feeding SRM-A or the HC/0.1\% diet. Fractions corresponding to VLDL, IDL/LDL, and HDL (as observed in nontransgenic mice on SRM-A) are indicated by bars $A$, $B$, and $C$, respectively.

descending aorta, and in the carotid arteries. The atherosclerotic lesions are classified in five categories as described in Methods. Examples of early and regular fatty streaks and mild, moderate, and severe plaques are shown in Fig. 4.

In Table III the mean number per mouse of early plus regular fatty streaks plus mild plaques on the one hand (Fig. 4, $b-d$ ) and the mean number per mouse of moderate plus severe plaques on the other hand (Fig. 4, $e$ and $f$ ) are presented. With either diet used, no signs of atherosclerosis were observed in nontransgenic littermates and in transgenic line 195 mice. With the LFC diet, causing severe hypertriglyceridemia but less severe hypercholesterolemia ( Table II), mice of lines 2 and 181 developed no or only very mild lesions. On the contrary, after HFC diets these lines developed severe atherosclerosis. An increase in the amount of cholate from 0.1 to $0.5 \%$ resulted in relatively more severe plaques per mouse. Line 181 mice, with the most severely elevated levels of cholesterol-rich VLDL- and IDL/LDL-sized lipoproteins on both HFC diets, were more
Table III. Atherosclerotic Lesions in APOE*3-Leiden Transgenic Mice on Different Diets

\begin{tabular}{|c|c|c|c|c|}
\hline \multirow{2}{*}{$\begin{array}{c}\text { Mouse } \\
\text { line }\end{array}$} & \multirow[b]{2}{*}{ SRM-A } & \multicolumn{3}{|c|}{ Diet } \\
\hline & & LFC & $\mathrm{HFC} / 0.1 \%$ & $\mathrm{HFC} / 0.5 \%$ \\
\hline & \multicolumn{4}{|c|}{ Number of fatty streaks/plaques per mouse* } \\
\hline Control & $-1-$ & $-1-$ & $-1-$ & $-1-$ \\
\hline 195 & $-1-$ & $-1-$ & $-1-$ & $-1-$ \\
\hline 2 & $-1-$ & $1.0 /-$ & $2.8 / 0.8$ & $2.0 / 3.0$ \\
\hline 181 & $-1-$ & $-1-$ & $1.0 / 2.5$ & $1.3 / 5.7$ \\
\hline
\end{tabular}

Semiquantitative analysis of atherosclerosis in groups of transgenic and nontransgenic mice was determined after $14 \mathrm{wk}$ of diet feeding. The values are the mean of at least three mice and represent the mean number of fatty streaks and mean number of plaques per mouse as observed during histological assessment as described in Methods. A dash means no lesions were observed. * Fatty streaks represent mild lesions of categories 1-3 (see Fig. 4, $b-d$ ); plaques represent severe lesions of categories 4 and 5 (see Fig. 4, $e$ and $f$ ).

susceptible to the formation of severe atherosclerotic plaques than line 2 mice. No differences were observed between males and females with respect to atherosclerosis susceptibility.

\section{Discussion}

Previously, we reported the generation of three different APOE*3-Leiden transgenic mouse lines (7). In the present study the effect of different semisynthetic cholesterol-containing diets on lipoprotein profiles is evaluated, with special reference to both the level and composition of VLDL/LDL-sized lipoproteins and on the development of atherosclerotic lesions. All three transgenic lines studied are more responsive to HFC feeding than nontransgenic littermates ( Table II). This responsiveness is positively correlated with the basal level of apo E3Leiden, despite the presence of endogenous mouse apo $\mathrm{E}$. The observation that the low expresser line 195 responded much less obviously to the different diets indicates that a threshold level of human apo E3-Leiden is required for developing hyperlipidemia with cholesterol feeding. There is some evidence that the amount of apo $\mathrm{E}$ may become rate-limiting in the clearance of remnant lipoproteins: $(a)$ the injection of apo $\mathrm{E}$ in rabbits has been shown to transiently reduce lipid levels (13), and $(b)$ overexpression of rat apo $\mathrm{E}$ in transgenic mice resulted in reduced lipid levels because of an increased clearance of VLDL and, consequently, resistance to diet-induced hypercholesterolemia $(14,15)$. These facts, taken together with our finding that overexpression of apo E3-Leiden leads to strongly elevated lipid levels, support our former conclusion that apo E3-Leiden behaves like a dominant trait in the expression of hyperlipoproteinemia in these transgenic mice, as in human beings. We hypothesize that on the surface of the remnant particles, apo E3-Leiden affects the proper conformation of the effective endogenous mouse apo $\mathrm{E}$ protein, providing the relative quantity of the apo E3-Leiden protein is high enough.

The semisynthetic diets used in this study are comparable with the diets defined by Nishina et al. (10) and are the first synthetic mouse diets that lead, like some nondefined diets, to the development of atherosclerotic lesions in inbred mice. In 

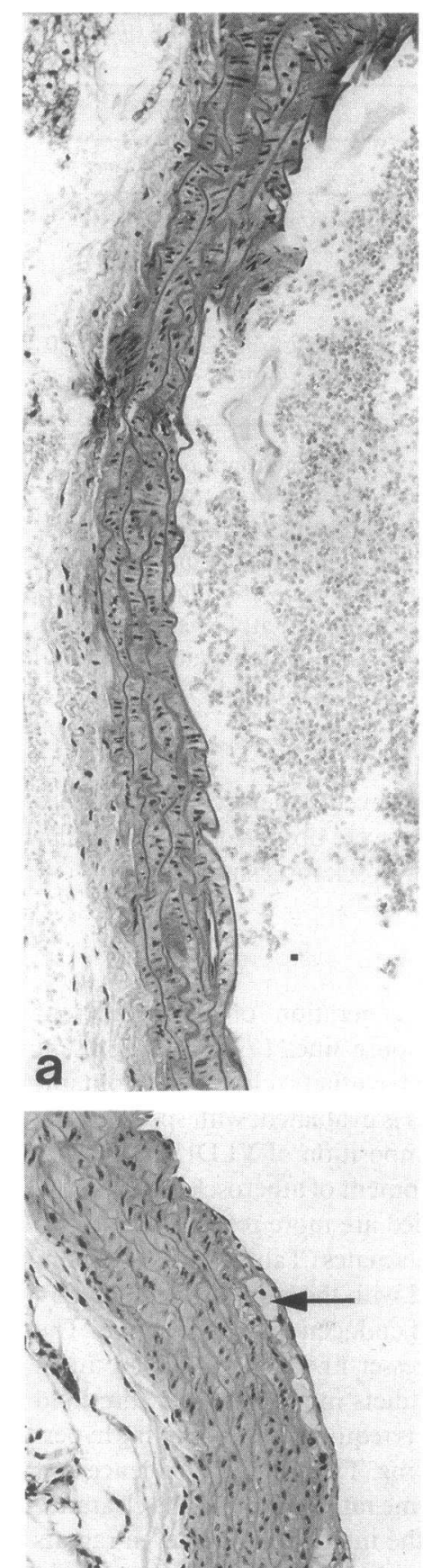

- E $\because, \frac{1}{2}$

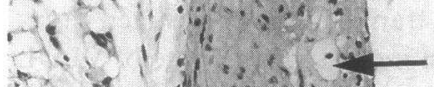

Dx 4 1 $\because 31.7$

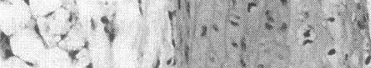

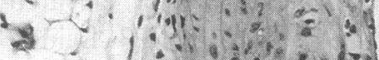

$,+2, \cdots, 3010$

$-1, \quad, \quad 30$

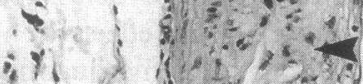

is lifin: ad

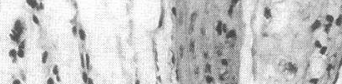

-1 14 in

d
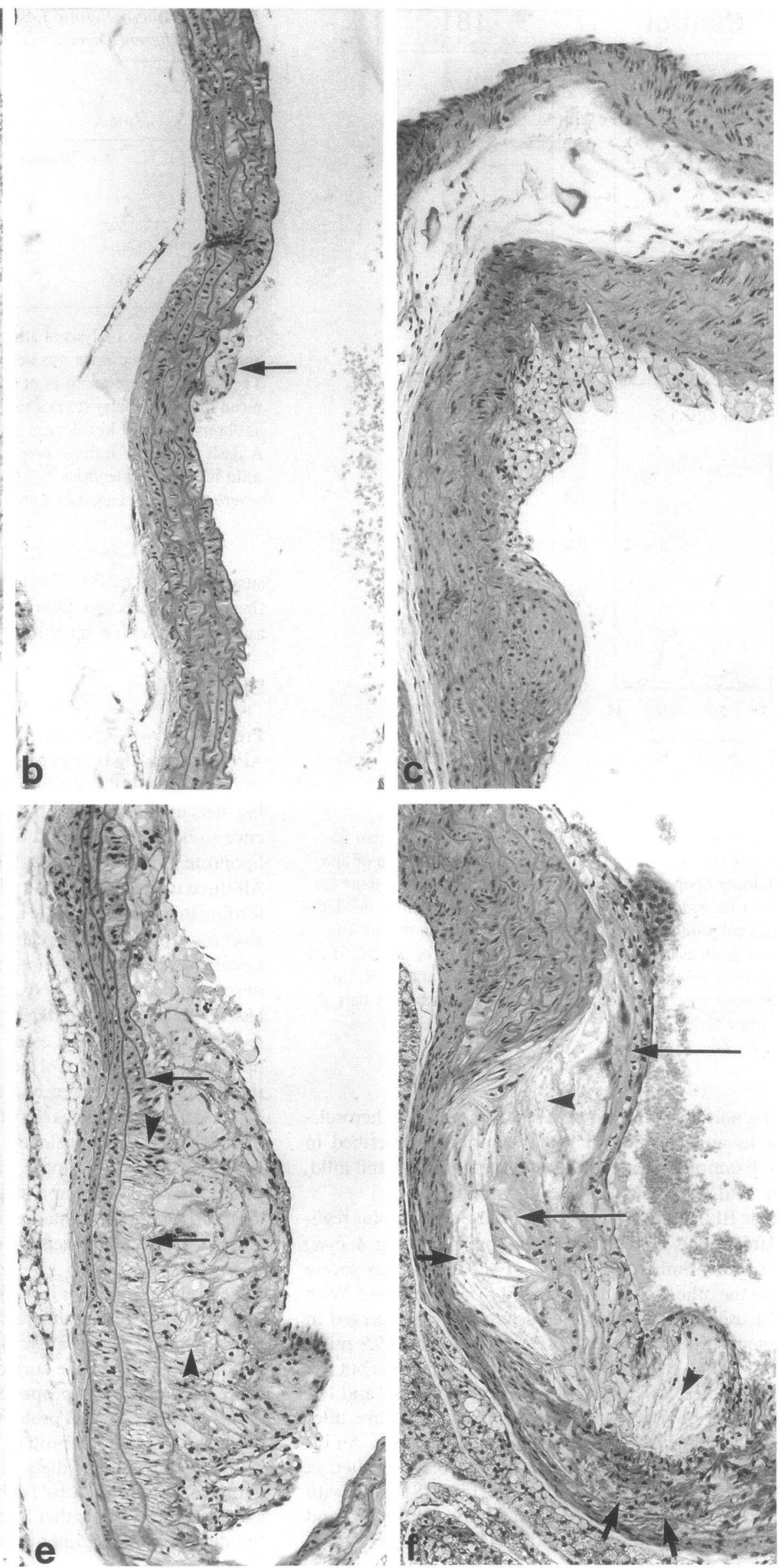
addition, these diets resulted in minimal lipid accumulation in the liver and formation of gallstones, which are prerequisites for proper studies regarding diet-induced hyperlipidemia. These diets contain sucrose (up to $50 \%$, Table I), which has been shown before to increase in humans and in some other animals the production and secretion of VLDL triglyceride by the liver, resulting in hypertriglyceridemia $(16,17)$. This increased hepatic lipogenesis can occur since fructose bypasses phosphofructokinase which is the rate-limiting enzyme in the glycolytic pathway (10). From the present study, it is obvious that the overproduction of VLDL having been fed sucrose also leads to hypertriglyceridemia in the APOE*3-Leiden transgenic mice, provided the transgene is expressed sufficiently ( Table II).

HFC diets resulted in severe hypercholesterolemia in high expressing transgenic APOE*3-Leiden mice, whereas serum triglyceride decreased as compared with the levels obtained after the LFC diet (Table II). A lowering of triglyceride levels concomitant with an increase in serum cholesterol in HFC diet-fed mice has been described before by LeBoeuf et al. (18, 19 ) and Paigen et al. (20). This effect was more pronounced with higher concentrations of cholate in the diets (Table II), which is in agreement with the results reported by Nishina et al. (10). Cholate facilitates the emulsification of cholesterol and triglyceride and thereby their intestinal absorption. However, whether cholate itself is the direct cause of lowering the triglyceride levels is at present subject to speculation.

In the high expressing lines 2 and 181 but not in the low expressing line 195, cholesterol increments also occurred in the HDL fraction, which is the result of the generation of relatively large and apo E-rich HDL particles (Figs. 2 and 3, Table II). The increase in these lipoproteins might be because of the fact that mice do not have cholesterol ester transfer protein activity $(21,22)$. Presumably, in normal mice and in line 195 these apo E-rich HDL particles will be cleared efficiently from the circulation through the LDL receptor with the endogenous mouse apo $\mathrm{E}$ as ligand, whereas in the high expressing APOE*3-Leiden mice this receptor-mediated clearance is disturbed.

The increase in serum cholesterol mainly occurred in the VLDL- and IDL/LDL-sized fractions and correlated positively with the level of expression of the transgene (Table II). In addition, in the VLDL- and IDL/LDL-sized fractions the cholesterol to triglyceride ratio increased after an HFC diet, especially at higher cholate concentrations in the diet, and concomitant with a redistribution of the apo E3-Leiden protein from HDL to this particular lipoprotein fraction (Fig. 2, Table II). Thus, cholesterol and apo E-rich remnant VLDL accumulate in the serum with cholesterol feeding.

The accumulation of cholesterol- and apo E-rich remnant lipoproteins in the plasma also occurs in patients with familial dysbetalipoproteinemia and is considered to be an atherogenic condition (5). Although the number of examined animals per group was small and the method of measuring atherosclerotic lesions was only semiquantitative, the development of athero- sclerotic lesions in the APOE*3-Leiden transgenic mice appeared to be positively correlated with the serum level of cholesterol-rich VLDL/LDL-sized lipoproteins.

Advanced human atherosclerotic lesions (plaques) are characterized by $(a)$ a fibrous cap, composed mostly of smooth muscle cells and connective tissue, $(b)$ a cellular area beneath the cap consisting of a mixture of macrophages and smooth muscle cells containing lipid droplets, and $(c)$ a deeper necrotic core which contains cellular debris, extracellular lipid droplets, cholesterol crystals, and calcium deposits $(23,24)$. Recently, it has been reported that homozygous apo E-deficient mice also develop extensive hyperlipidemia and atherosclerosis, even on a regular mouse diet (25-27). However, no evidence has yet been presented of cholesterol clefts, necrosis, and mineralization in these mice after $4 \mathrm{wk}$ of dietary treatment. It is possible that this period of dietary treatment is too short for the development of progressed atherosclerotic lesions. However, the possibility that the absence of apo $E$ protein on the surface of remnant particles leads to a different mechanism of generation of the lipid-laden macrophages in the fatty streaks and, eventually, to a different plaque histology may also not be excluded.

Our results clearly show that after 14 wk of cholesterol feeding the advanced atherosclerotic lesions in the APOE*3-Leiden transgenic mice do resemble their human counterparts: in these mice the plaques contain lipid-filled foam cells, fibrosis, necrotic areas, cholesterol crystals, and mineralization (Fig. 4). In these mice plaques developed not only near the sinus valves but also in the carotid arteries and in other parts of the aorta, especially near sites of arterial bifurcations. We did not find any atherosclerotic lesions in nontransgenic littermates that had been fed cholesterol. In contrast, Stewart-Phillips and Lough (28) did observe atherosclerosis in nontransgenic C57BL/6J mice having been fed cholesterol. The discrepancy between their results and our findings could be because of: $(a)$ the length of dietary treatment ( $35 \mathrm{vs} 14 \mathrm{wk}$ ), $(b)$ the fact that our nontransgenic littermates are not fully C57BL/6J inbred (F2 generation), and $(c)$ the fact that the lesions have been quantified using the HPS staining method. Although this method allows histological characterization of the lesions, it might be less suitable for detecting small fatty streaks as compared with the common lipid staining method with oil red $\mathrm{O}$.

We also did not find sex differences regarding the susceptibility to develop atherosclerotic lesions. This is in conflict with the results reported by Paigen et al. (29) and Warden et al. (30), showing that females are more susceptible to atherosclerosis than males. The absence of sex differences in our study might also be because of the rather semiquantitative method of measuring atherosclerotic lesions and to the relatively small numbers of mice analyzed.

We conclude that the APOE*3-Leiden transgenic mice present a suitable animal model system for studying the factors influencing the hepatic VLDL synthesis and their effect on the plasma level of atherogenic remnant lipoproteins. Moreover, since in these mice the plaque formation is reproducible and

Figure 4. Representative photographs of various stages of the atherosclerotic process observed in aorta and carotid arteries of transgenic APOE*3-Leiden mice. ( $a$ ) Aorta without lesions. $(b)$ Aorta with small fatty streak (arrow). $(c)$ Aorta with regular fatty streak. Media not affected. $(d)$ Aorta with mild plaque. Extension of foam cells into the media (arrow) and early fibrosis (arrowhead). Structure of the media intact. (e) Moderate plaque in a carotid artery with foam cells and cholesterol clefts (arrowhead). Media moderately affected. Note the interrupted internal elastic lamina (arrow). $(f)$ Severe plaque in aorta showing extensive destruction of the media. Note foam cells, cholesterol clefts, fibrosis (long arrow), multifocal necrosis (arrowhead), and mild mineralization (short arrow). All pictures represent HPS-stained slides $(\times 170)$. 
easily modifiable by administration of different diets and since plaque histology resembles that in humans, these mice may also be used for testing antiatherosclerotic drugs.

\section{Acknowledgments}

We are grateful to Mr. Jaap van Rijn for animal care and Miss Inge de Bruijn for analyses of tail DNA. Dr. Chris Zurcher and Dr. Ko Willems van Dijk are thanked for helpful discussions.

This research was supported by the Netherlands Heart Foundation (project 88.086), the Netherlands Foundation of Scientific Research (projects 900-504-092 and 900-539-117), and the Netherlands Royal Academy of Arts and Science (to M. H. Hofker).

\section{References}

1. Havel, R. J., Y.-S. Chao, E. Windler, L. Kotite, and L. S. S. Guo. 1980 Isoprotein specificity in the hepatic uptake of apolipoprotein $\mathrm{E}$ and the pathogenesis of familial dysbetalipoproteinemia. Proc. Natl. Acad. Sci. USA. 77:4349-4353.

2. Sherill, B. C., T. L. Innerarity, and R. W. Mahley. 1980. Rapid hepatic clearance of the canine lipoproteins containing only the $\mathrm{E}$ apoprotein by a high affinity receptor. J. Biol. Chem. 255:1804-1807.

3. Mahley, R. W. 1988. Apolipoprotein E: cholesterol transport protein with expanding role in cell biology. Science (Wash. DC). 240:622-630.

4. Mahley, R. W., T. L. Innerarity, S. C. Rall, Jr., K. H. Weisgraber, and J. M. Taylor. 1990. Apolipoprotein E: genetic variants provide insight into its structure and function. Curr. Opin. Lipid. 1:87-95.

5. Mahley, R. W., and S. C. Rall, Jr. 1989. Type III hyperlipoproteinemia (dysbetalipoproteinemia): the role of apolipoprotein $\mathrm{E}$ in normal and abnormal metabolism. In The Metabolic Basis of Inherited Disease. C. R. Scriver, A. L. Beaudet, W. S. Sly, and D. Valle, editors. McGraw-Hill Inc., New York. 11951213.

6. de Knijff, P., A. M. J. M. van den Maagdenberg, A. F. H. Stalenhoef, J. A. Gevers Leuven, P. N. M. Demacker, L. P. Kuyt, R. R. Frants, and L. M Havekes. 1991. Familial dysbetalipoproteinemia associated with apolipoprotein E3-Leiden in an extended multigeneration pedigree. J. Clin. Invest. 88:643-655.

7. van den Maagdenberg, A. M. J. M., M. H. Hofker, P. J. A. Krimpenfort, I. H. de Bruijn, B. van Vlijmen, H. van der Boom, L. M. Havekes, and R. R. Frants. 1993. Transgenic mice carrying the apolipoprotein E3-Leiden gene exhibit hyperlipoproteinemia. J. Biol. Chem. 268:10540-10545.

8. Simonet, W. S., N. Bucay, S. J. Lauer, D. O. Wirak, M. E. Stevens, K. H. Weisgraber, R. E. Pitas, and J. M. Taylor. 1990. In the absence of a downstream element, the apolipoprotein $\mathrm{E}$ gene is expressed at high levels in kidneys of transgenic mice. J. Biol. Chem. 265:10809-10812.

9. Simonet, W. S., N. Bucay, R. E. Pitas, S. J. Lauer, and J. M. Taylor. 1991 Multiple tissue-specific elements control the apolipoprotein E/C-1 gene locus in transgenic mice. J. Biol. Chem. 266:8651-8654.

10. Nishina, P. M., J. Verstuyft, and B. Paigen. 1990. Synthetic low and high fat diets for the study of atherosclerosis in the mouse. J. Lipid Res. 31:859-869.

11. Lopez-Virella, M. F., P. Stone, S. Ellis, and J. A. Colwell. 1977. Cholesterol determination in high-density lipoproteins separated by three different methods. Clin. Chem. 23:882-884.

12. Paigen, B., P. A. Holmes, D. Mitchell, and R. A. Williams. 1987. Quantitative assessment of atherosclerotic lesions in mice. Atherosclerosis. 68:231-240.

13. Mahley, R. W., K. H. Weisgraber, M. M. Hussain, B. Greenman, M.
Fisher, T. Vogel, and M. Gorecki. 1989. Intravenous infusion of apolipoprotein E accelerates clearance of plasma lipoproteins in rabbits. J. Clin. Invest. 83:21252130.

14. Shimano, H., N. Yamada, M. Katsuki, M. Shimada, T. Gotoda, K. Harada, T. Murase, C. Fukazawa, F. Takaku, and Y. Yakazi. 1992. Overexpression of apolipoprotein $\mathrm{E}$ in transgenic mice: marked reduction in plasma lipoproteins except high density lipoprotein and resistance against diet-induced hypercholesterolemia. Proc. Natl. Acad. Sci. USA. 89:1750-1754.

15. Shimano, H., N. Yamada, M. Katsuki, K. Yamamoto, T. Gotoda, K. Harada, M. Shimada, and Y. Yazaki. 1992. Plasma lipoprotein metabolism in transgenic mice overexpressing apolipoprotein E. Accelerated clearance of lipoproteins containing apolipoprotein B. J. Clin. Invest. 90:2084-2091.

16. Grundy, S. M., and M. A. Denke. 1990. Dietary influences on serum lipids and lipoproteins. J. Lipid Res. 31:1149-1172.

17. Witztum, J. L., and G. Schonfeld. 1978. Carbohydrate diet induced changes in very low density lipoprotein composition and structure. Diabetes. 27:1215-1229.

18. Lusis, A. J., B. A. Taylor, D. Quon, S. Zollman, and R. C. LeBoeuf. 1987. Genetic factors controlling structure and expression of apolipoproteins $B$ and $E$ in mice. J. Biol. Chem. 262:7594-7604.

19. LeBoeuf, R., D. Puppione, V. Schumaker, and A. Lusis. 1983. Genetic control of lipid transport in mice. I. Structural properties and polymorphisms of plasma lipoproteins. J. Biol. Chem. 258:5063-5070.

20. Paigen, B., A. Morrow, C. Brandon, D. Mitchell, and P. Holms. 1985. Variation in susceptibility to atherosclerosis among inbred strains of mice. Atherosclerosis. 57:65-73.

21. Agellon, L. B., A. Walsh, T. Hayek, P. Moulin, X. C. Jiang, S. A. Shelanski, and A. R. Tall. 1991. Reduced high density lipoprotein cholesterol in human cholesteryl ester transfer protein transgenic mice. J. Biol. Chem. 266:10796-10801.

22. Jiang, X. C., L. B. Agellon, A. Walsh, J. L. Breslow, and A. Tall. 1992. Dietary cholesterol increases transcription of the human cholesteryl ester transfer protein gene in transgenic mice. Dependence on natural flanking sequences. $J$. Clin. Invest. 90:1290-1295.

23. Munro, J. M., and R. S. Cotran. 1988. Biology of disease. The pathogenesis of atherosclerosis: atherogenesis and inflammation. Lab. Invest. 58:249-261.

24. Ishida, B. Y., and B. Paigen. 1989. Atherosclerosis in the mouse. In Genetic Factors in Atherosclerosis: Approaches and Model Systems. A. J. Lusis and S. R. Sparkes, editors. S. Karger, AG Basel. 189-222.

25. Plump, A. S., J. D. Smith, T. Hayek, K. Aalto-Setallä, A. Walsh, J. G. Verstuyft, E. M. Rubin, and J. L. Breslow. 1992. Severe hypercholesterolemia and atherosclerosis in apolipoprotein E-deficient mice created by homologous recombination in ES cells. Cell. 71:343-353.

26. Zhang, S. H., R. L. Reddick, J. A. Piedrahita, and N. Maeda. 1992. Spontaneous hypercholesterolemia and arterial lesions in mice lacking apolipoprotein E. Science (Wash. DC). 258:468-471.

27. Piedrahita, J. A., S. H. Zhang, J. R. Hagaman, P. M. Oliver, and N. Maeda. 1992. Generation of mice carrying a mutant apolipoprotein $\mathrm{E}$ gene inactivated by gene targeting in embryonic stem cells. Proc. Natl. Acad. Sci. USA. 89:4471-4475.

28. Stewart-Phillips, J. L., and J. Lough. 1991. Pathology of atherosclerosis in cholesterol-fed, susceptible mice. Atherosclerosis. 90:211-218.

29. Paigen, B., P. A. Holmes, D. Mitchell, and D. Albee. 1987. Comparison of atherosclerotic lesions and HDL-lipid levels in male, female, and testosteronetreated female mice from strains $\mathrm{C} 57 \mathrm{BL} / 6, \mathrm{BALP} / \mathrm{c}$, and $\mathrm{C} 3 \mathrm{H}$. Atherosclerosis. 64:215-221.

30. Warden, C. H., C. C. Hedrick, J. H. Qiao, L. W. Castellani, and A. J. Lusis 1993. Atherosclerosis in transgenic mice overexpressing apolipoprotein A-II. Science (Wash. DC). 261:469-472. 